\title{
Simple ways to improve undergraduate plastic surgery education
}

Sir,

We read with great interest the recent article "Plastic surgery for undergraduates: The basis of exceptional doctors as demonstrated by India." ${ }^{[1]}$ Lemon demonstrated that plastic surgery teaching is lacking in the undergraduate curriculum of $\mathrm{UK}^{[2]}$ medical schools and rightly puts forth the case that acquiring plastic surgery knowledge can make us better clinicians. We would like to share our own perspective 
on how undergraduate plastic surgery education can be improved.

Reforms in medical school curriculum have resulted in surgery, especially plastic surgery, being pushed down the order of priorities for undergraduate teaching and examination. ${ }^{2 \mid}$ Students are spending lesser time in their surgical rotations, with hours spent in surgery declining by up to $30 \%{ }^{[3]}$ Faced with very challenging examinations, students will often place their learning priorities on specialities that are exam-heavy.

Plastic surgery confuses many medical students and even doctors due to its versatility. ${ }^{[4]}$ The sheer diversity of procedures performed by plastic surgeons and the lack of anatomical boundaries in their work epitomises this but makes it difficult to define their role. The misconception of plastic surgery as a purely aesthetic speciality, perpetuated by misinformation, especially from the media, trivialises the work plastic surgeons do. ${ }^{[5]}$ Therefore, for plastic surgery to become a greater feature in the undergraduate curriculum, plastic surgeons should have greater involvement in designing future curricula.

It is our opinion that students should at least have a basic understanding of the management of congenital anomalies, burns, trauma, cancer and hand injuries. At the same time, we do acknowledge that it would be difficult to create a dedicated block for Plastic Surgery (as you would also find with surgical specialities like vascular surgery, cardiothoracic) without prolonging the undergraduate programme.

Fortunately, plastic surgery is a versatile speciality many other surgical specialties involve. Therefore, we would like to suggest that relevant plastic surgery teaching be incorporated alongside other surgical specialties (e.g., Breast Reconstruction with Breast Surgery Teaching, Hand Surgery with Trauma/Orthopaedics, Burns with Accident and Emergency teaching, Skin Cancer with Dermatology, Congenital Deformities with Paediatric Surgery), in order to maximise learning opportunities for students.

We can also look towards employing alternative teaching methods that keep up with current times. Advances in digital technology have transformed many aspects of our lives including the way we learn. E-learning has proved to be popular among post-graduate plastic surgery trainees, and medical schools should work toward replicating that at the undergraduate level. ${ }^{[6]}$ The majority, if not all, of medical students own mobile devices with smartphone capabilities. With smartphone applications for plastic surgery trainees already in the market, medical schools should attempt to develop plastic surgery applications for the undergraduate medical student. ${ }^{[7]}$ Plastic surgery has always evolved with time and is the surgical speciality at the forefront of innovation. Plastic surgeons can keep up this tradition of innovation by adapting their teaching methods in line with modern digital technology.

The principles of plastic surgery are universally applicable in all branches of medicine and the underestimation of its value in the undergraduate curriculum needs to be addressed.

\section{Nigel Yong Boon Ng, Mark Twoon \\ School of Medicine, University of Aberdeen, Scotland, United Kingdom}

Address for correspondence: Nigel Yong Boon Ng, Suttie Centre, Foresterhill Campus, University of Aberdeen, Aberdeen, AB25 2ZD, United Kingdom. E-mail: nigelybng@gmail.com

\section{REFERENCES}

1. Lemon TI. Plastic surgery for undergraduates: The basis of exceptional doctors as demonstrated by India. Indian J Plast Surg 2014;47:269.

2. Lemon TI. Anglo-French comparison study of plastic surgery teaching. J Res Med Educ Ethics 2014;4:203-8.

3. Agha RA, Papanikitas A, Baum M, Benjamin IS. The teaching of surgery in the undergraduate curriculum: Reforms and results. Int J Surg 2004;2:74-6.

4. Agarwal P. Perception of plastic surgery in the society. Indian J Plast Surg 2004;37:110-4.

5. Wade RG, Clarke EL, Leinster S, Figus A. Plastic surgery in the undergraduate curriculum: A nationwide survey of students, senior lecturers and consultant plastic surgeons in the UK. J Plast Reconstr Aesthet Surg 2013;66:878-80.

6. Stevens RJ. Do trainees want e-learning in plastic surgery? J Plast Reconstr Aesthet Surg 2011;64:e47-9.

7. Amin K. Smartphone applications for the plastic surgery trainee. J Plast Reconstr Aesthet Surg 2011;64:1255-7.

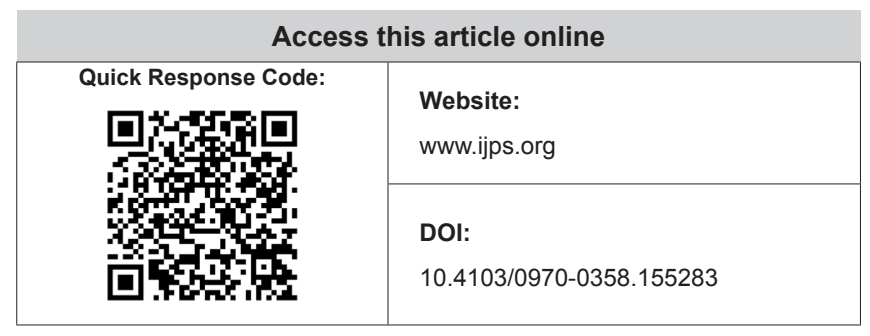

Indian Journal of Plastic Surgery January-April 2015 Vol 48 Issue 1 